\title{
Alcohol Use Disorders and Associated Factors among an Elderly Community Sample in Nigeria: A Cross-Sectional Survey
}

\author{
Kingsley Mayowa Okonoda ${ }^{*}{ }^{\circledR}$, Bawo Onesirosan James ${ }^{2}$, \\ Christopher Goson Piwuna ${ }^{1}$, Esther Awazzi Envuladu ${ }^{3}$ \\ ${ }^{1}$ Department of Psychiatry, University of Jos, Jos, Plateau State, Nigeria \\ ${ }^{2}$ Drug Abuse Treatment Education and Research (DATER) Unit, Federal Neuropsychiatric Hospital, Benin-City, Edo State, Nigeria \\ ${ }^{3}$ Department of Community Medicine, University of Jos, Jos, Plateau State, Nigeria \\ Email: *mayorking2001@yahoo.com
}

How to cite this paper: Okonoda, K.M., James, B.O., Piwuna, C.G. and Envuladu, E.A. (2020) Alcohol Use Disorders and Associated Factors among an Elderly Community Sample in Nigeria: A Cross-Sectional Survey. Open Journal of Psychiatry, 10, 114-126. https://doi.org/10.4236/ojpsych.2020.103012

Received: April 14, 2020

Accepted: May 17, 2020

Published: May 20, 2020

Copyright $\odot 2020$ by author(s) and Scientific Research Publishing Inc. This work is licensed under the Creative Commons Attribution International License (CC BY 4.0).

http://creativecommons.org/licenses/by/4.0/

\begin{abstract}
Background: Alcohol Use Disorders (AUDs) in the elderly are associated with impairments in physical, psychological, social and cognitive functioning. Both the elderly men and women who drink alcohol are at a greater risk of social isolation and economic deprivation and the women in particular are in the danger of rapid development of dependence a phenomenon termed "telescoping" dependence. This study seeks to determine the prevalence of alcohol use disorders as well as their associated factors among the elderly in Jos South LGA, Plateau State, Nigeria. Methods: A community-based cross-sectional study of elderly ( $\geq 60$ years) men and women. A total of 400 out of a total of 422 elderly community dwellers identified were interviewed with the aid of a composite questionnaire incorporating the socio-demography, Alcohol Smoking and Substance Involvement Screening Test (ASSIST), Mini International Neuropsychiatric Interview (MINI) and the 12-item General Health Questionnaire (GHQ-12). Results: The lifetime and current prevalence of alcohol use were $69.8 \%$ and $45.5 \%$ respectively. The prevalence of AUDs was $(\mathrm{n}=52,13.0 \%)$. AUDs was significantly associated with being male $(\mathrm{OR}=$ 2.57, 95\%CI: 1.35 - 3.77, $\mathrm{p}<0.01)$. Participants with AUDs were more likely to report difficulty ambulating $\left(\chi^{2}=0.34,0.56\right)$, cardiovascular $\left(\chi^{2}=0.42, \mathrm{p}=\right.$ $0.52)$, respiratory $\left(\chi^{2}=0.55, \mathrm{p}=0.46\right)$, and digestive $\left(\chi^{2}=0.17, \mathrm{p}=0.68\right)$ problems, though not statistically significant. Similarly, no significant associations were seen with probable psychiatric co-morbidity $\left(\chi^{2}=2.35, \mathrm{p}=0.13\right)$ and chronic pain $\left(\chi^{2}=0.52, \mathrm{p}=0.47\right)$. Conclusions: Alcohol use and use disorders were common in this elderly cohort. AUDs were associated with poorer health indices.
\end{abstract}




\section{Keywords}

Alcohol Use Disorders, Prevalence, Elderly, Correlates, Nigeria

\section{Introduction}

The use of psychoactive substances is a burden to the health, social and economic wellbeing of individuals, families and community. It is estimated that over 2 billion people use alcohol, 1.3 billion smoke (tobacco) and 185 million are drug users globally [1]. Alcohol and other substances are more commonly used among young adults. However, the expected rise in the proportion of older adults may lead to an increase among elderly people who abuse alcohol and other substances [2].

Alcohol continues to be the most commonly abused substance among the elderly despite the fact that the prevalence of alcohol use disorders (AUDs) declines with age [3]. AUDs are associated with widespread impairments in physical, psychological, social and cognitive functioning. It has been illustrated that a history of heavy drinking in elderly men is associated with a fivefold increase in the risk of developing a psychiatric disorder [4].

Alcohol may account for an unexplained depressive illness in the elderly ("boozer's gloom") as well as unexpected withdrawal symptoms which may occur in "secret drinkers" when they are admitted [5]. Elderly patients are particularly susceptible to risk of alcohol use disorders due to changing metabolism, body composition and poor general health which all influence the effects of alcohol and the risks associated with consumption [2]. Both the elderly men and women who drink alcohol are at a greater risk of social isolation and economic deprivation and the women in particular are in the danger of rapid development of dependence a phenomenon termed "telescoping" dependence [2] [6].

Prescription medications like tranquilizers, analgesics, sedatives, stimulants and even antidepressants tend to be misused by the elderly because they usually have conditions that make the use of these medications common in them. Among these; the opiates and benzodiazepines seem to be the most misused. Unlike in the case of alcohol where being male is a greater risk of abuse, being female, being socially isolated and having a history of substance abuse or other psychiatric illnesses are factors more likely to be associated with prescription drug abuse in the elderly. Benzodiazepines in particular have been known to be associated with cognitive loss and mood symptoms and may be associated with confusions and falls [6].

Despite all the above problems associated with alcohol and substance use in the elderly, detection by medical personnel is poor leading to under-diagnosis, misdiagnosis and under treatment. Health professionals also tend to attribute symptoms of alcohol and substance use/disorders to other common morbidities in the elderly like dementia, depression, other psychiatric illnesses and other 
physical illnesses common in old age [2] [7]. All these conditions can also either be causes for substance use or they can be exacerbated by substance use.

There have been a large number of studies by different researchers in Nigeria on the subject of psychoactive substance use and disorders [8] [9] [10]. Most of these have been on alcohol, either in the general adult population, in youths, in population subgroups such as students or hospital patients and some in the community, while some have been on psychoactive substances in general either in subgroups of the population, in hospital patients or in the community. Very few have been on alcohol or other drugs in the elderly [11].

This study seeks to determine the prevalence of alcohol use disorders as well as their associated factors among the elderly in Jos South LGA, Plateau State, Nigeria.

\section{Methodology}

\subsection{Study Design}

The study was a community-based cross-sectional study.

\subsection{Study Setting}

This study was conducted in Kuru, located some $20 \mathrm{~km}$ to Jos, the capital of Plateau State. Kuru is a conglomerate of several villages and hamlets within Jos South LGA. The indigenous language spoken in Jos South is Berom but Hausa is generally spoken and is the language of business. The estimated population of Kuru in the last National Population censors of 2006 was 36,054. The predominant occupation of the town's residents is farming.

\subsection{Study Population}

The study population was elderly men and women, aged 60 years and above residing in the community, at least not less than 6 months preceding the commencement of the study.

\subsection{Sample Size}

The projected sample size that was required to meet the set objectives at 95\% CI was calculated using the formula

$$
N=Z^{2} p q / d^{2}
$$

where $n=$ minimum sample size, $z=$ standard normal deviation at $95 \%$ of the confidence interval, a constant $=1.96, p=$ proportion of the elderly with lifetime use of alcohol from a previous study which was $45.2 \%=0.452^{25}$ (11); $q=$ complementary probability $=1-\mathrm{p}=(1-0.452)=0.548 ; \mathrm{d}=$ precision level $5 \%=$ 0.05 . A minimum sample of 381 was calculated, but increased to 419 , to allow for a $10 \%$ non-response or attrition rate.

\subsection{Inclusion/Exclusion Criteria}

All elderly men and women from ages 60 years and above who have resided in 
the community for more than 6 months were included. Elderly Patients who are too acutely ill to get into meaningful clinical engagement were excluded from the study.

\subsection{Sample Technique}

Kuru was purposively selected based on anecdotal reports of high rates of use of alcohol and other psychoactive substances by her residents. However, there was no documented study on the rate of use and its effects in the community.

The estimated population of the elderly 60 years and above in Kuru in the last nationwide censors in 2006 obtained from the office of National Population Commission in Jos was 1530. Due to the limited number of elderly in the community and the exploratory nature of the, a total population sampling of all the elderly individuals in the community was done and all elderly members of the community who met the inclusion criteria and gave consent were recruited into the study until the sample size was achieved. The selection of participants was done from house to house. A house mapping was conducted to identify all the houses where the elderly resides and the total number of such houses was noted.

All houses in the town were enumerated, and each house having an elderly person aged 60 years and above were mapped. Using the above process, a total of 422 elderly community dwellers were identified. Out of this number, 16 declined consent and 3 were too ill to respond while 3 others gave very scanty information that their responses could not be used.

Data was collected using a composite questionnaire and was interviewer administered. The data collection instrument was translated to Hausa language and back translated to the English language by two professionals (a linguist and a psychiatrist) fluent in English and Hausa, so as to ensure content validity of the tool.

\subsection{Instruments}

Socio-demographic questionnaire capturing gender, age, education, income (personal and family), work/occupation (including current regular professional work, other occupations in retirement, non-professional work, voluntary), ethnicity, religion, marital status, living status.

- Social Network (existence of a person who participant can count on in difficult moments);

- Lifestyle, physical activity, self-reported health status;

- History of chronic physical or mental illness;

- Functional status: assessed by a five-item scale eliciting basic household independency, ability to take medicines, bathe/comb hair/dress, ability to eat without support, and physical functioning-walk, sit, lie down, get around indoors, and go upstairs;

- Use of health service: number of doctor visits in the last 12 months and/or hospitalizations in the last 12 months.

General Health Questionnaire 12-item The GHQ-12 was chosen because of its brevity and ease of completion. The validity of the GHQ- 12 has been reported to 
be comparable with that of the longer versions of the GHQ in the identification of minor psychiatric disorders. For the purpose of this study, the GHQ scoring method (0-0-1-1) was chosen over the simple Likert scale of $0-1-2-3$, as this particular method is believed to help eliminate any biases which might result from the respondents who tend to choose responses 1 and 4 or 2 and 3, respectively [13]. The GHQ-12 had been previously validated [14] and extensively used in Nigeria [15] [16] [17].

The Alcohol, Smoking, and Substance Involvement Screening Test (ASSIST): The ASSIST was developed by the World Health Organization for screening in primary and general medical care settings and has since been considered as an instrument of choice when the goal is to address a range of different psychoactive substances [18]. This test categorizes respondent's substance use into low, moderate and high risks on the bases of their scores. With scores of 0 - 10 for alcohol and 0 - 3 for illicit drugs, participants are considered as having a low risk for health and other problems from their use of alcohol and other drugs (AODs), 11 - 26 for alcohol and $4-26$ for other drugs indicate moderate risks while $>26$ indicates high risk for health and other problems from their current use of alcohol and other drugs and are likely to be dependent. The ASSIST was used in a previous study [9], and took an average of 3.85 - 6 minutes to administer to the research participants.

Mini International Neuropsychiatric Interview (Alcohol Section): The MINI was used in this study. Responses were rated at the right of each question by circling either "Yes" or "No". The MINI is a short structured clinical interview that helps researchers to make diagnoses of psychiatric disorders according to DSM-IV or ICD-10. The MINI was designed for epidemiological studies and clinical trials and is divided into modules identified by letters, each corresponding to a diagnostic category [19]. At the beginning of each diagnostic module, screening question (s) are made to the corresponding main criteria of the disorder, after which diagnostic box(es) permit the clinician to indicate whether the diagnostic criteria are met. This module took approximately $1-2$ minutes to administer in this study.

The ASSIST Feedback Report Card was used in this study to provide substance-specific involvement scores based on calculated standard ASSIST scoring procedures. The scores ranged from $0-10=$ low, $11-26=$ moderate, and $27+=$ high. Research participants within the low score range on the ASSIST are interpreted as being at "low" risk of health and other problems related to substance use. Finally, participants whose scores fall within the "moderate-high" range will be evaluated as being at "moderate-high" risk of experiencing severe problems as a result of their current use and are likely dependent on the psychoactive substance.

\subsection{Data Collection}

Data was collected from 17th to 31st August, 2018. The data collection team comprised of total of eight [8] trained research assistants; psychologists, social 
workers and interns. They received training in the content and administration of the data collection instruments as well as the objectives of the study and more importantly, how to carry out the data collection in a non-judgmental way. The research assistants could speak English, Hausa and Berom. The data collection instruments were pretested among elderly people in a different community. This helped determine average time of administration of the instrument and helped to detect and correct minor ambiguities.

\subsection{Data Analysis}

Data was analysed using SPSS version 23 statistical software after imputing into an excel sheet and exporting to the SPSS. The dependent variable was substance use/disorder (present/absent). Independent variables were: socio-demographic characteristics, social network, self-reported health status, psychiatric morbidity and use of health services.

Frequencies and percentages were used to calculate the prevalence of psychoactive substance use/disorders. The Chi-squared test categorical associations with level of significance set at $\mathrm{p}<0.05$.

\subsection{Ethical Consideration}

Approval for this study was obtained from the Ethics Committee of the Jos University Teaching Hospital (JUTH). Permission was sought from the district head of Kuru after explaining the nature and purpose of the study. Due to limited formal education in most of the cohort, the purpose of the study was read out to participants in the presence of a significant other, and informed verbal consent or thumb-printed signed forms were obtained.

All participants who screened positive on ASSIST and those diagnosed with AUDs on Mini International Neuropsychiatric Interview (MINI) were counseled adequately, given brief intervention or referred to the Psychiatry clinic of the hospital for management as the case may be.

\section{Results}

\subsection{Sociodemographic Characteristics}

A total of 400 out of a total of 422 elderly community dwellers identified were interviewed.

The sample was predominantly female ( $\mathrm{n}=242 ; 60.5 \%)$, aged between the 60 69 years' age group $(n=249 ; 62.3 \%)$ with a mean age was 69.19 years. All but one of the respondents were Christians. Only 11 respondents were living alone, while $144(36 \%)$ lived with a spouse or with their children $(\mathrm{n}=139 ; 34.8 \%)$. The majority of respondents were married $(230,57.5 \%)$ and a total of $157(39.3 \%)$ respondents were widowed.

Over half (59\%) had no formal education, and past-month employment status of respondents showing that $111(39.8 \%)$ were unemployed. Majority of the respondents $(n=235,58.8 \%)$ were farmers. Seventy-nine percent of respondents 
earned between N1000 to N10,000 and only $12.8 \%(\mathrm{n}=51)$ earned above N21,000. See Table 1.

\subsection{Clinical Characteristics}

Nearly a third (30.8\%) reported their current health status as "bad". While a majority of participants reported having chronic pain $(\mathrm{n}=267,66.8 \%)$, those with cardiovascular $(n=58,14.5 \%)$, respiratory $(n=15,3.8 \%)$, digestive $(n=172,43 \%)$

Table 1. Socio-demographic characteristics of participants.

\begin{tabular}{|c|c|c|}
\hline Variable & Frequency & Percentage \\
\hline \multicolumn{3}{|l|}{ Sex } \\
\hline Male & 158 & 39.5 \\
\hline Female & 242 & 60.5 \\
\hline \multicolumn{3}{|l|}{ Age class } \\
\hline $60-69$ & 249 & 62.3 \\
\hline $70-79$ & 86 & 21.4 \\
\hline $80-89$ & 44 & 11.0 \\
\hline$\geq 90$ & 21 & 5.3 \\
\hline \multicolumn{3}{|l|}{ Religion } \\
\hline Islam & 1 & 0.3 \\
\hline Christianity & 399 & 99.7 \\
\hline \multicolumn{3}{|l|}{ Ethnicity } \\
\hline Berom & 384 & 96.0 \\
\hline Others & 16 & 4.0 \\
\hline \multicolumn{3}{|l|}{ Living status } \\
\hline Alone & 11 & 2.8 \\
\hline With others & 389 & 97.2 \\
\hline \multicolumn{3}{|l|}{ Marital status } \\
\hline With partner & 105 & 26.2 \\
\hline Without partner (single, divorced, separated) & 295 & 73.8 \\
\hline \multicolumn{3}{|l|}{ Education } \\
\hline No formal education & 236 & 59.0 \\
\hline Completed primary education & 89 & 22.2 \\
\hline Secondary education & 75 & 18.8 \\
\hline \multicolumn{3}{|l|}{ Employment status } \\
\hline Unemployed & 107 & 26.8 \\
\hline Employed (regular + occasional) & 198 & 49.5 \\
\hline Retired & 95 & 23.7 \\
\hline \multicolumn{3}{|l|}{ Income } \\
\hline$\leq \mathrm{N} 10,000$ & 316 & 79.0 \\
\hline N11,000 - N20,000 & 33 & 8.2 \\
\hline$>\mathrm{N} 20,000$ & 51 & 12.8 \\
\hline
\end{tabular}


conditions were in the minority. Over half screened positive on the GHQ-12 with probable psychiatric morbidity $(n=224,56.0 \%)$. See Table 2 .

\subsection{Prevalence and Correlates of Alcohol Use Disorders}

The lifetime and current prevalence of alcohol use were $69.8 \%$ and $45.5 \%$ respectively. The prevalence of alcohol use disorder (AUD) in this study was ( $\mathrm{n}=$ 52, 13.0\%) (see Table 3).

AUD was significantly associated with being male (OR $=2.57,95 \% \mathrm{CI}$ : 1.35 3.77, $\mathrm{p}<0.01)$, but not living alone $(\mathrm{p}=0.16)$. Participants with AUDs were more likely to report cardiovascular $\left(\chi^{2}=0.42, \mathrm{p}=0.52\right)$, respiratory $\left(\chi^{2}=0.55, \mathrm{p}\right.$ $=0.46)$, digestive $\left(\chi^{2}=0.17, \mathrm{p}=0.68\right)$, difficulty ambulating $\left(\chi^{2}=0.34,0.56\right)$, probable psychiatric co-morbidity $\left(\chi^{2}=2.35, \mathrm{p}=0.13\right)$ and chronic pain conditions $\left(\chi^{2}=0.52, \mathrm{p}=0.47\right)$, but the relationships did not attain statistical significance.

Table 2. Clinical related characteristics of participants.

\begin{tabular}{|c|c|c|}
\hline Variable & Frequency & Percentage \\
\hline \multicolumn{3}{|c|}{ Self-reported health status } \\
\hline $\mathrm{Bad}$ & 123 & 30.8 \\
\hline Regular & 133 & 33.2 \\
\hline Very good & 144 & 36.0 \\
\hline \multicolumn{3}{|c|}{ Cardiovascular condition? } \\
\hline Present & 58 & 14.5 \\
\hline Absent & 342 & 85.5 \\
\hline \multicolumn{3}{|c|}{ Respiratory condition? } \\
\hline Present & 15 & 3.8 \\
\hline Absent & 385 & 96.2 \\
\hline \multicolumn{3}{|c|}{ Digestive condition? } \\
\hline Present & 172 & 43.0 \\
\hline Absent & 228 & 57.0 \\
\hline \multicolumn{3}{|c|}{ Chronic pain? } \\
\hline Present & 267 & 66.8 \\
\hline Absent & 133 & 33.2 \\
\hline \multicolumn{3}{|c|}{ Difficulty ambulating? } \\
\hline Present & 73 & 18.2 \\
\hline Absent & 327 & 81.8 \\
\hline \multicolumn{3}{|c|}{ Number of hospital admissions } \\
\hline Nil & 356 & 89.0 \\
\hline 1 & 35 & 8.8 \\
\hline$\geq 2$ & 9 & 2.2 \\
\hline \multicolumn{3}{|c|}{ Probable psychiatric morbidity (GHQ) } \\
\hline Present & 224 & 56.0 \\
\hline Absent & 176 & 44.0 \\
\hline
\end{tabular}


Table 3. Prevalence of alcohol use and use disorder among participants.

\begin{tabular}{ccc}
\hline Variable & Frequency & Percentage \\
\hline Lifetime alcohol use & & \\
Yes & 278 & 69.8 \\
No & 122 & 30.2 \\
& & \\
Current alcohol use (past 3 months) & 182 & 45.5 \\
Yes & 218 & 54.5 \\
No & & \\
Level of risk for alcohol use (ASSIST) $\mathbf{n}=182$ & 67 & 36.8 \\
Low & 90 & 49.5 \\
Moderate & 25 & 13.8 \\
Severe & & \\
Alcohol Use Disorder (MINI) & & 13.0 \\
Present & 52 & 87.0 \\
Absent & 348 & \\
\hline
\end{tabular}

\section{Discussion}

The difference between the prevalence of lifetime and current alcohol use found in this study suggests a decline in the use of alcohol as the respondents got older. This is in keeping with the expected decline of alcohol use and AUDs with age although it still remains the most commonly abused of all psychoactive substances in older adults [3]. Blay et al. [20] reported an almost 100\% current use rate among older residents in Brazil, while in South Africa, lifetime and current use rates were $23.7 \%$ and $10.7 \%$ respectively [21]. An earlier report from Nigeria, indicates lifetime and current use rates of $45.2 \%$ and $15.6 \%$ respectively [11]. Rates also decrease when compared across older age bands, with rates of $65.8 \%$ among people aged 50 - 64 years, $63.6 \%$ among people 65 years and above and past year prevalence of use of $23.6 \%$ and $13.8 \%$ respectively [22]. While the proportion of males with lifetime alcohol use was slightly higher $(72.8 \%)$ than that of the females (67.8\%), there was an almost equal proportion for current use in both genders. There is evidence that though women drink less often than men, they are more likely to start drinking in old age compared to men [23].

The prevalence of AUDs in this study; 13\% (abuse: 4.5\%, dependence: $8.5 \%$ ) was higher than rates from Brazil [20] [24]. However, the use of the MINI; a diagnostic instrument limits direct comparison with studies utilising screening instruments. For example, one study from South Africa assessed heavy drinking (defined as $>7$ drinks/week) and binge drinking ( $>3$ drinks/one occasion/week) and found that $4 \%$ of participants reported heavy drinking and $3.7 \%$ binge drinking [21]. Paradoxically, this study found that the rate of abuse among older adults was less, when compared to that of dependence $8.5 \%$. The reason for this is not clear, but it is probable that co-morbidities in the elderly may make them progress faster to dependence states. 
Elderly males were nearly three times more likely to be diagnosed with AUD, a finding which is consistent with earlier reports in different population groups and settings [8] [9] [10] [11] [22] [25]-[31]. Gender differences may be explained by socio-cultural norms which tolerate male drinking. Further more women also tend to become more quickly intoxicated than men limiting the quantity of alcohol they can realistically take [11].

Male gender is a well-known factor in alcohol excessive alcohol use and alcohol use disorder in the older adults. Older men are at a much higher risk of developing alcohol-related problems compared to older women [3] [32]. Blay et al. found that alcohol misuse was higher in older men (25.3\%) than in women (2.9\%) while Nogueira et al. also working in Brazil found that lifetime alcohol misuse frequency of $16.8 \%$ in men was considerably higher than $2.5 \%$ observed in women [20] [24]. Their controlled analysis also revealed that male gender was the strongest factor related with lifetime alcohol misuse [24]. Pelzer and Phaswana-Mafuya also found that there were higher rates of problem drinking among men in a South African older adult population [21]. This was also the finding of Lasebikan and Gureje in Nigeria who found that excessive drinking was confined to men [11].

There was no significant association between AUD and self-reported health status and any of the medical conditions, number of hospital admissions and probable psychiatric morbidity. This is similar to previous studies which also found no association of risky drinking with hypertension, diabetes and depression [21]; nor association between alcohol and functional status, vascular conditions, respiratory problems, kidney problems, bone fracture or self-reported health just like this study [24].

Many other previous studies have not made diagnosis of AUD in older adults but limited themselves to the use of screening instruments or some operational definitions of problem drinking and/or binge drinking. This makes it difficult to compare our findings.

This study is limited by the following; firstly, the Cross sectional nature of the study precludes drawing causal inference from the associations that we found.

Secondly, the screening instrument, ASSIST and diagnostic instrument MINI were all based on self-reports and participants could have denied the consumption of alcohol and other substances and their complications when actually they do.

Lastly, self-report of chronic health conditions might have been affected by a lack of awareness of the presence of a particular health problem by the participants.

\section{Conclusions}

Alcohol use remains highly prevalent both in the lifetime use and current use among older adults. As expected there is a decline in the current use against lifetime use which indicates a decline in use with age. Particularly, there was no difference in gender in regards to alcohol use in this study.

There was a high prevalence of AUDs among older adults in this community. It was surprising that the prevalence of alcohol abuse was lower than alcohol 
dependence as expected. But this also lays credence to the high prevalence of alcohol use and the factors in old age leading to rapid development of dependence.

Older adults with AUDs were most likely to be males and there was no significant association between AUD and self-reported health status and any of the medical conditions, number of hospital admissions and probable psychiatric morbidity.

\section{Acknowledgements}

Funding: Research reported in this publication was supported by the Fogarty International Center (FIC); Office of the Director (OD/NIH); National Institute of Neurological Disorders and Stroke (NINDS/NIH); and the National Institute of Nursing Research (NINR/NIH) of the National Institutes of Health under Award Number. D43 TW010130. The content is solely the responsibility of the authors and does not necessarily represent the views of the National Institutes of Health.

We also like to acknowledge the staff of Netwealth Centre for Addiction Management and Psychological Medicine, Rantya, Jos for the data collection and providing Brief Intervention where appropriate.

\section{Conflicts of Interest}

The authors declare no conflicts of interest regarding the publication of this paper.

\section{References}

[1] Anderson, P. (2006) Global Use of Alcohol, Drugs and Tobacco. Drug and Alcohol Review, 25, 489-502. https://doi.org/10.1080/09595230600944446

[2] Wang, Y.P. and Andrade, L.H. (2013) Epidemiology of Alcohol and Drug Use in the Elderly. Current Opinion in Psychiatry, 26, 343-348. https://doi.org/10.1097/YCO.0b013e328360eafd

[3] Ross, S. (2005) Alcohol Use Disorders in the Elderly. Primary Psychiatry, 12, 32-40.

[4] Saunders, P.A., Copeland, J.R.M., Dewey, M.E., Davidson, I.A., Mcwilliam, C., Sharma, V., et al. (1991) Heavy Drinking as a Risk Factor for Depression and Dementia in Elderly Men. The British Journal of Psychiatry, 159, 213-216. https://doi.org/10.1192/bjp.159.2.213

[5] Desai, T.H., Rajput, A.H. and Desai, H.B. (1990) Use and Abuse of Drugs in the Elderly. Progress in Neuro-Psychopharmacology \& Biological Psychiatry, 14, 779-784. https://doi.org/10.1016/0278-5846(90)90048-L

[6] Sarkar, S., Parmar, A. and Chatterjee, B. (2015) Substance Use Disorders in the Elderly: A Review. Geriatric Mental Health, 2, 74.

https://doi.org/10.4103/2348-9995.174271

[7] Han, B., Gfroerer, J.C., Colliver, J.D. and Penne, M.A. (2009) Substance Use Disorder among Older Adults in the United States in 2020. Addiction, 104, 88-96. https://doi.org/10.1111/j.1360-0443.2008.02411.x

[8] Okonoda, K., Nanribet, M., Kenneth, Y. and Onesirosan, J. (2017) Alcohol Use Disorders among Participants of a Community Outreach in Jos, Nigeria: Prevalence, Correlates and Ease of Acceptance of Brief Intervention. Journal of Medical Science 
and clinical Research, 5, 22049-22056. https://doi.org/10.18535/jmscr/v5i5.127

[9] Okonoda, K.M., Mwoltu, G.N., Arigbede, O.O. and Yakubu, K. (2017) Psychoactive Substance Use in a Sample of Community Outreach Participants; Prevalence, Correlates and Ease of Incorporating Care. International Journal of Research in Medical Sciences, 5, 2845. https://doi.org/10.18203/2320-6012.ijrms20172572

[10] Akinsulore, A., Fatoye, F., Awaa, O., et al. (2012) Psychoactive Substance Use among Psychiatric Out-Patients in a Nigerian Teaching Hospital. Nigerian Journal of Psychiatry, 10, 2-7.

[11] Lasebikan, V.O. and Gureje, O. (2015) Lifetime and 7-Day Alcohol Consumption in the Elderly, Prevalence and Correlates: Reports from the Ibadan Study of Aging. African Journal of Medicine and Medical Sciences, 44, 33-41.

[12] Mo, A. (2008) Research Methodology with Statistics for Health and Social Sciences. Nathadex Publications, 2, 115-122.

[13] Goldberg, W. (1991) User's Guide to the General Health Questionnaire. Handbook of Psychiatric Measures. Berkshire, Nfer-Nelson, England, 75-79.

[14] Gureje, O. and Obikoya, B. (1990) The GHQ-12 as a Screening Tool in a Primary Care Setting. Social Psychiatry and Psychiatric Epidemiology, 25, 276-280. https://doi.org/10.1007/BF00788650

[15] Adebowale, T. and Adelufosi, A. (2013) Stress and Minor Psychiatric Morbidity among Nigerian Executives: Some Socio-Demographic and Biological Correlates. Annals of Medical and Health Science Research, 3, 412. https://doi.org/10.4103/2141-9248.117946

[16] Issa, B.A., Yussuf, A.D., Olanrewaju, G.T. and Abiodun, O.A. (2014) Mental Health of Doctors in a Tertiary Hospital in Nigeria. The Pan African Medical Journal, 19, 178. https://doi.org/10.11604/pamj.2014.19.178.3642

[17] Abdulmalik, J.O., Adedokun, B.O. and Baiyewu, OO. (2014) Prevalence and Correlates of Mental Health Problems among Awaiting Trial Inmates in a Prison Facility in Ibadan, Nigeria. African Journal of Medicine and Medical Sciences, 43, 193-199.

[18] Humeniuk, R., Henry-Edwards, S., Ali, R., Poznyak, V. and Monteiro, M. (2010) ASSIST-Linked Brief Intervention for Hazardous and Harmful Substance Use. World Health Organization.

[19] Sheehan, D.V., Lecrubier, Y., Sheehan, K.H., Amorim, P., Janavs, J., Weiller, E., et al. (1998) The Mini-International Neuropsychiatric Interview (M.I.N.I.): The Development and Validation of a Structured Diagnostic Psychiatric Interview for DSM-IV and ICD-10. Journal of Clinical Psychiatry, 2018, 22-33. https://doi.org/10.1037/t18597-000

[20] Blay, S.L., Fillenbaum, G.G., Andreoli, S.B. and Gastal, F.L. (2009) Correlates of Lifetime Alcohol Misuse among Older Community Residents in Brazil. International Psychogeriatrics, 21, 384-391. https://doi.org/10.1017/S1041610208008326

[21] Peltzer, K. and Phaswana-Mafuya, N. (2013) Problem Drinking and Associated Factors in Older Adults in South Africa. African Journal of Psychiatry, 16, 104-109. https://doi.org/10.4314/ajpsy.v16i2.13

[22] Gureje, O., Degenhardt, L., Olley, B., Uwakwe, R., Udofia, O., Wakil, A., et al. (2007) A Descriptive Epidemiology of Substance Use and Substance Use Disorders in Nigeria during the Early 21st Century. Drug Alcohol Depend, 91, 1-9. https://doi.org/10.1016/j.drugalcdep.2007.04.010

[23] Menninger, J.A. (2002) Assessment and Treatment of Alcoholism and SubstanceRelated Disorders in the Elderly. Bulletin of the Menninger Clinic, 66, 166-183. https://doi.org/10.1521/bumc.66.2.166.23364 
[24] Nogueira, E.L., Cataldo Neto, A., Cauduro, M.H.F., Ulrich, L.E.F., Spanemberg, L., DeCarli, G.A., et al. (2013) Prevalence and Patterns of Alcohol Misuse in a Community-Dwelling Elderly Sample in Brazil. Journal of Aging and Health, 25, 1340-1357. https://doi.org/10.1177/0898264313506461

[25] Atilola, O., Ayinde, O. and Adeitan, O. (2013) Beyond Prevalence and Pattern: Problematic Extent of Alcohol and Substance Use among Adolescents in Ibadan South-West Nigeria. African Health Sciences, 13, 777-784. https://doi.org/10.4314/ahs.v13i3.37

[26] Wakawa, A. and Sale, S. (2014) Prevalence, Predictors and Patterns of Psychoactive Substance Use among HIV Seropositive Adults at Aminu Kano Teaching Hospital Kano, North Western Nigeria. International Journal of Medical Sciences, 1, 2315-9844.

[27] Chukwujekwu, C.D., Ugochukwu Okeafor, C. and Omamurhomu Olose, E. (2017) Epidemiology of Alcohol Use Disorders among Psychiatric Patients in a Tertiary Hospital in Nigeria. Journal of Addiction Research and Therapy, 8, 309. https://doi.org/10.4172/2155-6105.1000309

[28] Adamson, T.A. (2015) Descriptive National Survey of Substance Use in Nigeria. Journal of Addiction Research and Therapy, 6, 234. https://doi.org/10.4172/2155-6105.1000234

[29] Abiodun, A.B. and Sajo, O.A.S. (2014) Alcohol and Psychoactive Substance Use among Medical Students of the University of Ilorin, Nigeria. European Scientific Journal, 10, 69-83.

[30] Bamiso, M.A. and Naimat, B.O. (2014) Correlates and Predictive Factors for Alcohol and Other Psychoactive Substance Use among Tanker Drivers in Ilorin, Nigeria. African Journal of Psychiatry, 17, 132.

[31] Abdulmalik, J., Omigbodun, O., Beida, O. and Adedokun, B. (2009) Psychoactive Substance Use among Children in Informal Religious Schools (Almajiris) in Northern Nigeria. Mental Health Religion \& Culture, 12, 527-542. https://doi.org/10.1080/13674670902832813

[32] Dar, K. (2006) Alcohol Use Disorders in Elderly People: Fact or Fiction? Advances in Psychiatric Treatment, 12, 173-181. https://doi.org/10.1192/apt.12.3.173 